\title{
Sustainability In and for Software Engineering with Six Sigma
}

\author{
Farhana Rizvi \\ Faculty of Computer Science, \\ Preston University Kahot, \\ Islamabad Campus
}

\begin{abstract}
Programming designers are favored Green IT now a days same like Agile, Green Software. Everybody is keen on feasible advancement where somebody does not have issues in sustainable development they emphasize in and for programming designing. Customary programming, building routines does not help the green programming, designing improvement most normal green programming, designing advancement routines is suitability as Sustainable Development makes numerous Problems. Users may overcome such issues by the exclusion of this strategy for improving standard in and for sustainability using six sigma for the pillars of software engineering in support of five interconnected domains Environment, Economics, Politics, social and Technologies. The application of activities supporting the change of these angles is depicted and how they might be utilized as an instrument as a part of sustainable to enhance these domains. Guidelines for support of Sustainable Development are provided to overcome and to reduce the variances in the product and processes by eradicating defects that interfere with customer satisfaction and guarantees quality assurance and hardware accuracy that it works at its maximum capacity and optimize the flow of layered technologies using tool DMAIC of Six Sigma.
\end{abstract}

\section{Keywords}

Sustainable, domains, Environment, Economics, Politics, social and Technologies, layered technologies, DMAIC, Six Sigma.

\section{INTRODUCTION}

The majority of programming architects lean toward green Information Technology (IT), Agile and Green Software. They are keen on supportable improvement where they do not have issues which feasible advancement confronts in and for programming building. In programming Engineering product framework and computer code are design.

\subsection{Domains of Sustainability}

In sustainable advancement, Resources are ideal for addressing the needs of human while considering the Environmental, Economic, Political, Technologies and Social effects. The product building history is secured long time. It has gone a few eras of presentation of techniques and systems for building up the immense complex framework. Yet customary devices are not underpinned the parts of sustainability. Efforts are being made to help the depiction of these perspectives into Software Engineering with the vital administration.[1]

The domains of sustainability are shown in figure 1 .

\author{
Malik Sikander Hayat Khiyal, PhD \\ Professor Faculty of Computer Sciences, \\ Preston University Kahot, \\ Islamabad Campus
}

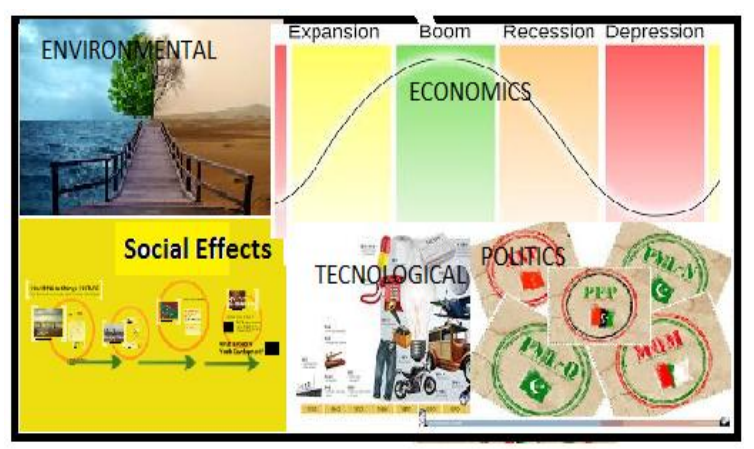

Fig 1: Five Domains of Sustainability

\section{LITERATURE REVIEW}

\subsection{Comparison between Sustainability and Traditional Software Engineering.}

The statement Sustainability is gotten from Latin Sustainer. Sustainability means maintain, help or continue. It has been utilized in, 1980 as a part of the feeling of human sustainability on the planet. As indicated by the most widely recognized and significant meaning of sustainability. "Sustainable Development is improvements that rally the necessities of a today without trading off the capacity of future eras to address their own particular needs". [1] In Software Engineering product framework with the machine code are made. Software Engineering is around 50 years of age. It is the study and application of Engineering to outline, improvement and upkeep of programming. The application of a product trained, quantifiable methodology for the improvement, operation and support of programming. [1]

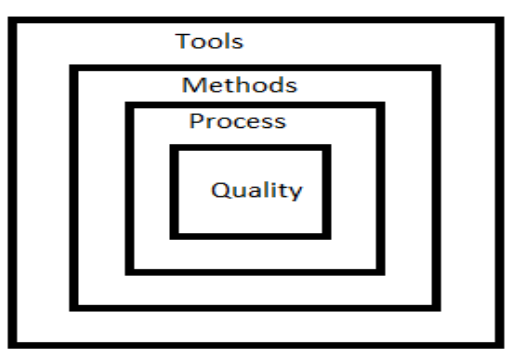

Fig 2: Layered Technology

Figure 2 represents the concept of layer technology; these are pillars of software engineering while developing a software process in \& for. Every layer involved in this diagram represents the aim for programming advancement that is required after a progression of steps. These steps are known as Software Process. In the Software Engineering this procedure 
is performed on the Layer structure. These Layers are Quality, process, methods and tools. Most building methodologies have taken after the hierarchical steps for the enhanced quality. Its deepest layer is a quality center layer "quality". It is the blend of value requirements. These quality necessities are three sided. This layered technology clarifies the stream of value for five domains environment, economic, political, societal, and technologies. [2]

Any enterprise success depends on its value. These requirements should be according to one side layer of customer requirements. Customer requirements depend on the value of a product or service. They don't care about enterprise functions and how an enterprise will create its values. Different opinions of management experts that are focusing on functional concern and can take enterprise as a whole. Otherwise, they focus on process or value. We can determine the quality of the product by its process [3] and can improve the product quality with the process improvement. Due to this Six Sigma was developed to reduce the variance in the process. We can get the improved quality product with improved process. It means Stakeholder values are determined and activities are either related to the creation of the final value or not. Processes are evaluated on how effectively and efficiently they create values. Effectiveness is defined as delivering what the customer requires, or exceeding the requirements; it encompasses quality, price, delivery, timeliness and everything else that goes into perceived value. Efficiency is defined as being effective while using minimum resources; more of an owner's perspective. Excellent processes are those that are both effective and efficient. Viable utilizing a base of assets is a greater amount of a manager's point of view. Amazing techniques are those that are both powerful and productive. Stream chart of quality requirements are given in figure 3 .

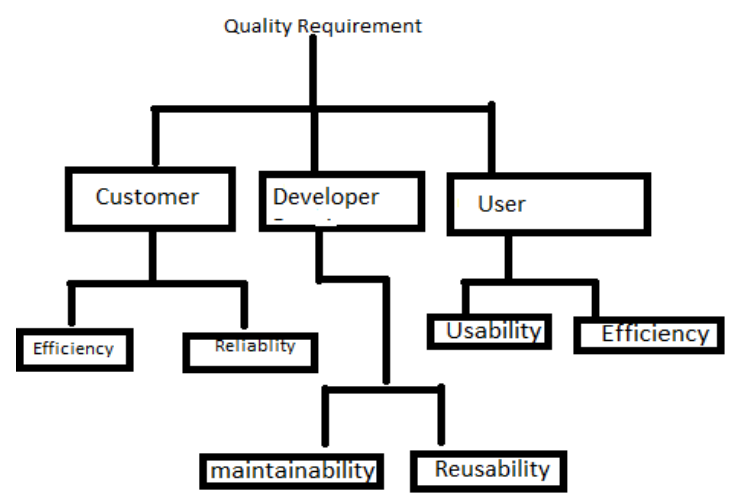

Fig 3: Stream chart of Quality Requirement

Some quality prerequisites are hard to explain in an obvious manner. Programming details are normally inadequate and regularly conflicting. The procedure is a progression of moves or steps made to accomplish a characterized structure. Steps for example which specializes in techniques are connected; work items, for example, models, reports, information, reports, structures, and so on are created, developments are made, quality is guaranteed, and change is appropriately overseen.

Different systems utilized as a part of Software Engineering are called Software Engineering routines. Program building strategies give the specialized ability to building programming. Systems will incorporate prerequisites examination, configuration, program development, Testing and backing. Programming building devices give modified or mostly customized.

Backings for the "Procedure" Tools are coordinated with the goal that data made by one apparatus can be utilized by an alternate. Economic advancement, key Domains is ecological, Environmental, social, innovative and political. Reasonable improvement is most widely recognized advancement system in Green programming Engineering. We have need for a reasonable definition. Reasonable programming as a product whose advancement, arrangement and utilization brings about insignificant immediate and indirect negative effects or even positive effects on the economy and environment. All these things were inconceivable in programming designing. When any product building apparatus is utilized it might be helpful or it might have unsafe effect on the economy, society and human, beings for example It may be costly. When an instrument is presented, an alternate such device was easy to understand, everyone can utilize it effectively and it is according to customer requirements. It has requested in the business sector. On the off chance that this apparatus would be simpler to handle everybody will be attempting to utilize it and get the output. This device will be suited in hot climate and helpful in achieving targets. We didn't have any such application in our conventional programming, designing which has been enhanced the execution of our advancement instruments.

\subsection{Characterizing sustainability in and for software Engineering}

Sustainability was indicated by two ideas in the commission report, Prime Requirements and Limited assets and needs are available for future requirements [4]. The authors judge against the vitality productivity of diverse programming [5]. Other authors assess contending programming plan by an extra measurement [6]. Object advancement stages are discussed in [7]. Satisfaction of prerequisites for each of the five domains in a practical way is discussed in [8]. [9] May get realists objective with the sustainable software process. Realists mean that sustainability objectives and result will be counted as requirements. Support for the assessment of economic plan that postures theoretical questions discussed in [10]. Methodology is to make ample situations for the idea of manageability [11]. Develop software that meets the needs of users while reducing environmental impacts [12]. Also it can be seen in the concurring reports of World Bank's environmental sustainability; the file is demonstrating positive relationships that higher salary is corresponded with higher environmental Sustainability [13]. Author in [14] additionally recommends that the three measurements or "Domains" mirror the controls of the individuals who study sustainability, including for good measure that a social and a political column could likewise be incorporated. According to Robert et al [15] show how new approaches and tools are increasing day by day in sustainable development. Six Sigma has been being embodied in the management strategy for quality improvement. Quantitatively evaluate organization's processes and to reduce process variability [16].

After different reviews a framework should be designed where product and process are According to the primary requirements of user and customer satisfaction and define quality standards within limited resources which have less variety and defects. This framework should clarify the stream of value for five domains Environmental, Economic, Political, Technologies and Social Effects.

We reduce the variances in the processes by eradicating defects that interfere with customer satisfaction and 
guarantees for quality assurance and hardware accuracy that it works at its maximum capacity. Six Sigma has been visualized as the managerial strategy for quality improvement by quantitatively estimating organization's processes and reducing process variation in software process for five domains as in use of layered technology quality enhancement.

\subsection{Six Sigma}

Six Sigma is a strategy that gives organizations of the devices a chance to enhance the capacity of their business forms. This increment in execution and decline in procedure variety prompts deformity lessening and tremendous change in benefits, worker assurance and the nature of the item. A company's performance is measured by the sigma level of their business processes. Traditionally, companies accepted three sigma performance levels as the norm, despite the fact that these Processes created between 6,200 and 67,000 problems per million opportunities! The Six Sigma standard of 3.4 problems per million opportunities is a response with the increasing expectations of customers and the increased complexity of Modern products and processes.

Six Sigma has been imagined as the managerial technique for quality change by quantitatively assessing the association's methods and lessening methodology changes. Six Sigma is depicted regarding three perspectives:

- Philosophy: Six Sigma can be utilized for enhancing customer's satisfaction and being more beneficial by eliminating defects.

- Metrics: As main metric:

$\begin{array}{lll}\checkmark & \text { Dpmo (defects Per Million } \\ & \text { Opportunities). } \\ \checkmark & \text { Defect rate (problems Per Million) } \\ \checkmark & \text { Dpu (defects every Unit) } \\ \checkmark & \text { Yield. }\end{array}$

- Improved structure: Six Sigma claims diverse toolkits and organized discriminating deduction frameworks, for example, DMAIC and DFSS (Design For Six Sigma). We are utilizing DMAIC .[17]

We are attempting to track on these angles in the software engineering. An alternate idea about sustainability is that keeping the capacity of a framework over a characterized time compass. We can clarify the standard meaning of sustainability by two purposes of perspectives.

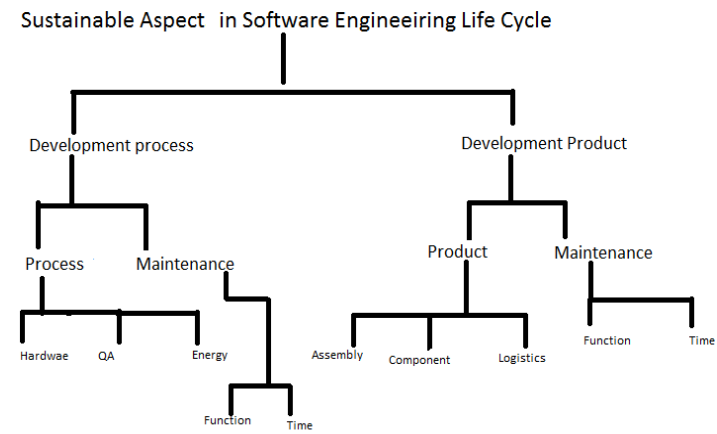

Fig 4: Sustainable aspects in the software engineering life cycle.

Figure 4 is utilizing this stream to clarify the proposed procedures. It is specified that we need to overcome such issues by the prohibition of this methodology for enhancing standard in and for sustainability by utilizing these supportable viewpoints as a part of programming designed life cycle. This stream defines the two phases, Development Process and Development Product. In the Development process Sustainability amid the beginning programming advancement procedure implies improvement with mindful utilization of environmental, social, and economic resources. Sustainability of the product framework amid its support period until supplanted by another framework incorporates nonstop observing of quality and knowledge management. In the Development product Sustainability of the product framework as item concerning its utilization of assets for creation is attained to, for instance, by utilizing green IT standards, reasonably created equipment parts, and improving the obliged logistics for getting together, and so forth.

\subsection{Conceptual Model for Software Six Sigma}

Based on Six Sigma, Software Six Sigma [18] is introduced for the adoption of Six Sigma methodologies and toolkits in the software area, especially in reducing the defects in software development life cycles to improve the software product quality and increase customer satisfaction. Software Six Sigma covers all aspects of the software development life cycle with DMAIC methodologies. With the help of various toolkits Software Six Sigma can target reduce variances in the process and less defective product to the organizations with immediate returns so that highest benefits can be achieved in a short period of time. It collaborates with other software process improvement approaches.

\subsection{Sustainable Six Sigma Analyzer}

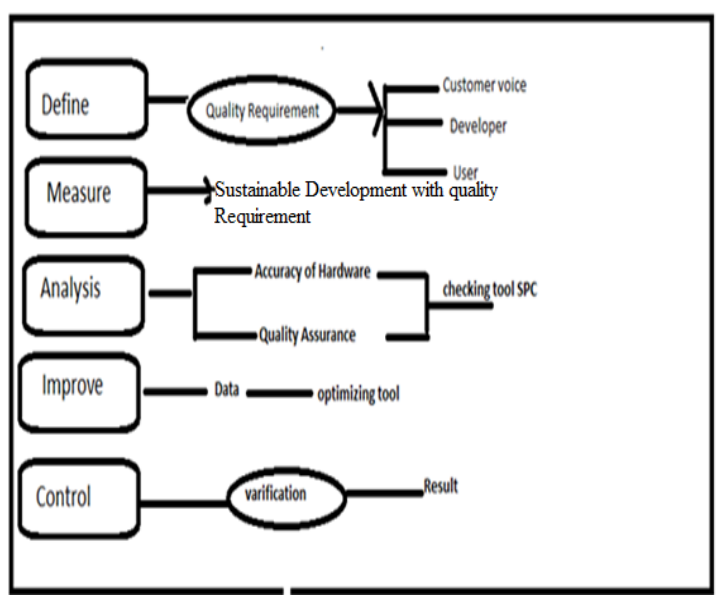

Fig 5: Sustainable Six Sigma Analyzer

The figure 5 represents the methodology of Sustainable Six Sigma (SSS) Analyzer for the proposed solution of the problem. Six Sigma can interpret in these five domains. The purpose is to enhance standards to maintain in and for sustainable development.

Six Sigma framework for programming strategy updates can help and energize the gathering of Programming Six Sigma. With this spark, the connected Analyzer of Software Six Sigma was developed, what's all the more considering this sensible Analyzer, we proposed the Six Sigma structure, which involves Six Sigma DMAIC method, Six Sigma apparatuses SPC and FMEA, can lessen the fluctuations in the methodologies by destroying abandons that meddle with customer satisfaction, and guarantees for quality assurance and hardware accuracy that it works at its maximum capacity. We completed this framework with an analyzer, called Sustainable Six Sigma Analyzer(SSS).The proposed framework and SSS are useful in beginning and executing Six Sigma endeavors, empowering data collection and data 
examinations by Six Sigma tool store, and organizing the Six Sigma wander execution change to achieve Six Sigma wander destinations and of affiliations' business goals. Feasible Six Sigma Analyzer (SSS) is as yet being taken a shot at and testing.

\section{SIX SIGMA METHODOLOGY: DMAIC}

Applying the DMAIC Steps in Development Process are as: A typical Six Sigma methodology for existing as different commercial enterprise programming, designing is likewise confronted with the test of enhancing the proficiency and benefit of their organizations. To do this, they have to comprehend the best philosophy and instruments to study and break down techniques effectively. Truth be told, to enhance comes about, the best approach is to enhance the process that issues you those products. Process improvements have 5 phases: define, measure, analyze, improve and Control. DMAIC methodology can be used to find problems in existing processes and fix them for improvements. It can also be used to expand the current capabilities of an existing process by identifying opportunities to improve current processes. Each phase of DMAIC as given in figure 6 is explained in subsections

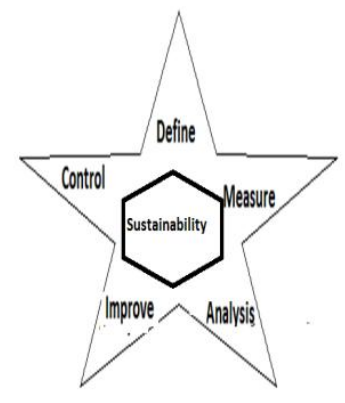

Fig 6: Phase of DMAIC with Sustainability

\subsection{Define Module}

Define stage will characterize item objective adjusted to the customer, developer and user necessities inside five domains of sustainability.

\subsubsection{Creation of a Problem Statement}

We concentrate on Sustainable perspectives of designing the product and Process by the five Domains and attempt to upgrade the level of domain in the advancement of In and For Software Engineering. The variances in the product and processes is reduced by eradicating defects that interfere with the customer's satisfaction and guarantee for quality assurance and hardware accuracy that it works at its maximum capacity. Six Sigma has been visualized as the managerial strategy for quality improvement by quantitatively estimating organization's processes and reducing process variation in software process for five domains as in use of layered technology quality enhancement [18].

- Sustainability in System: When character Six Sigma is a thorough, centered and very compelling execution of demonstrated Quality standards and methods. Fusing components of the work of numerous quality pioneers, Six Sigma goes from essentially blunder free business execution.
- Eradicating in system, it has less prompted and circuitous adverse or constructive outcome on Environment, Economic.

- $\quad$ Social Effects and Political issues. Furthermore, term depends upon the endeavor.

- Sustainability for Process: When describing for the system can perform that insignificant prompt and underhanded negative or constructive outcome on society, singular, environment, society and legislative issues. Moreover, now is the perfect time depends upon the task.[19] When describing in system, it has less prompted and deviant contrary or beneficial outcome on society, individual, environment, society and administrative issues. Also, compass depends on upon the errand. When describing for structure can perform that immaterial quick and distorted adverse or beneficial outcome on society, individual, environment, society and administrative issues. Likewise now is the ideal time depends on upon the endear

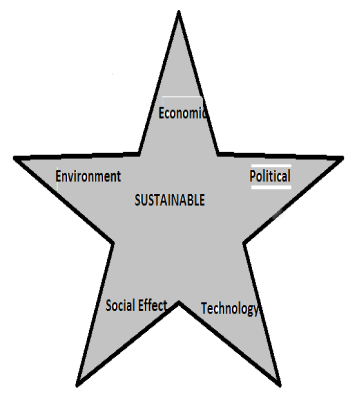

Fig 7: Sustainable Development with Quality Requirement

The figure 7 shows the sustainable development with quality requirement.

These quality requirements are three sided. Three sided means customer, Developer and user. How five domains of sustainability will be possible with the fulfillment of three sides of quality requirements?

Goal: Our aims are to maintain the standard for the development of sustainability in and for using Six Sigma with the help of layer technology. Six Sigma emphasizes setting extremely high Objectives, collecting data, and analyzing results to a fine degree as a way to reduce defects in In (Products) and For (process) 


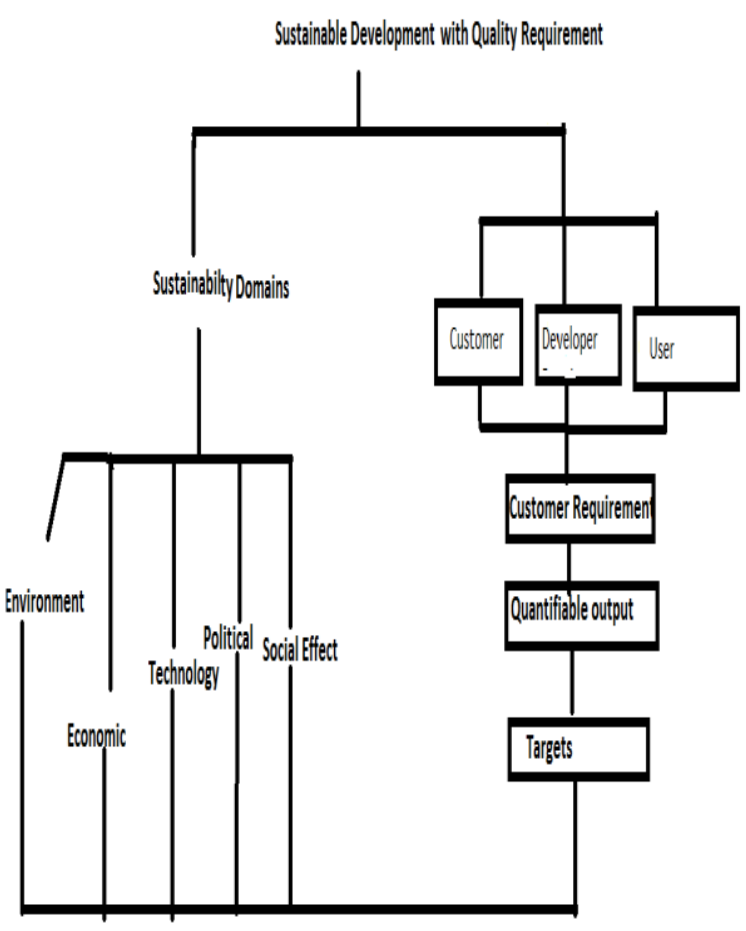

Fig 8: Sustainability in five domains with Quality Requirement

This Figure shows how we can improve five domains in the framework of Six Sigma and perspective of improving quality and maintain sustainability. Six Sigma tries to search such ways and role of sustainable indicators which will be helpful to recognize the main sources of defects and guarantee quality assurance and hardware accuracy that it works at its maximum capacity. It will improve the quality of process outputs and maintain sustainability in all domains.[20]

\subsection{Measure}

Measure stage will gauge the vitality utilization amid methodological advancement. Among estimation, all areas are considered.

Fig 9: Pareto Analysis for yield and sigma value

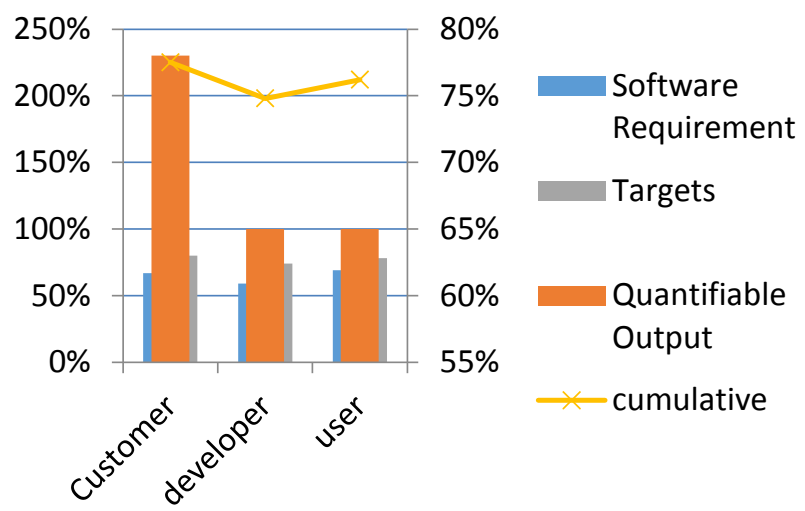

Figure 9 Pareto chart showing the sustainable development with quality Requirements Sustainable Development with quality Requirement will be possible following the Philosophy and Metrics of Six Sigma. We can calculate the yield and sigma value.
Yield and Sigma calculation: Six Sigma can be utilized for enhancing customer satisfaction and Being more beneficial by eliminating defects. The Defects Per Million Opportunities (DPMO) were at 8136. A Six Sigma approach was initiated to improve the quality of deliverables. The goal is to improve yield from 99.01 to 99.19 and the sigma value from $3 \sigma$ to more than $3.9 \sigma$.

\subsection{Analysis}

Analysis stage is to distinguish the approaches to check the equipment precision and give the quality affirmation with SPC (Statistical process control) apparatuses.

(SPC) is a technique for quality control which utilizes measurable routines. SPC is connected with a specific end goal to screen and control a procedure.

Process execution was evaluated utilizing Cause-and-Effect outlines, to disconnect key issue territories, to study the foundations for the deviation from perfect execution, and to distinguish if there is a relationship between them.

\subsubsection{Root Cause Analysis and Preventive Measures Determination}

During analysis, implementation of changes to remove these variances and improve the quality. Expert people can understand about wrong or right attempts to remove systematic defects [21].

The defects are classified based on their types. A Pareto chart shown in figure 10 is prepared to show the defect Category with the highest frequency of occurrence - the target.

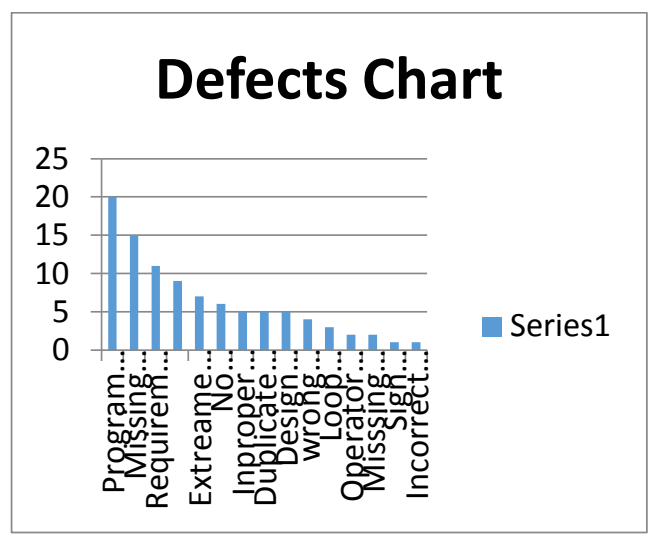

Fig 10: List of Defects Categories

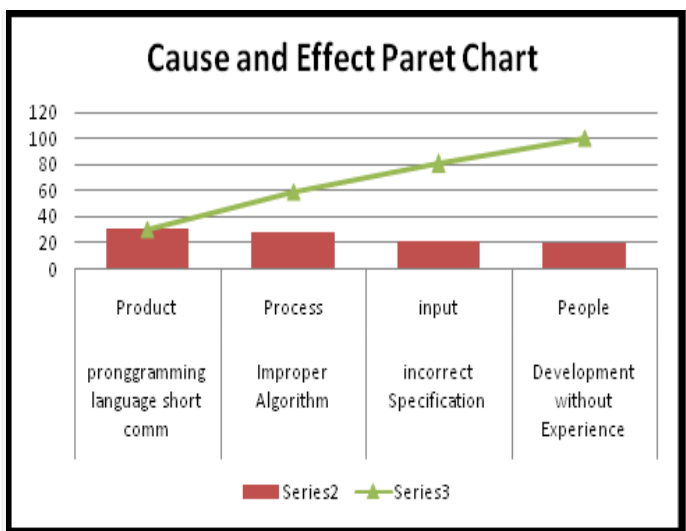

Fig 11: Cause and Effect Pareto Chart Analysis 
The figure 11 shows the Pareto chart which is explaining the main causes of

(i) Variances of product and process without sustainable development.

(ii) Our customer is not satisfied or not getting their quality requirements with in limited resources.

(iii) Developers are not experienced and used to new technologies and approaches.

(iv) To utilize new approaches and tools to maintain the standards of the development of sustainability, realist's objective with the sustainable software process.

They are not used to maintain and reuse the product.

(vi) User is unable to use a product efficiently.

With the help of FMEA, it is identified that all the probable failure modes for the product or process. It prioritizes the failure modes for focused attention by using a scoring model based on Severity (S), Occurrence (O) and Detect ability (D).

\section{$\mathrm{RPN}=\mathrm{S} * \mathrm{O} * \mathrm{D}[28]$}

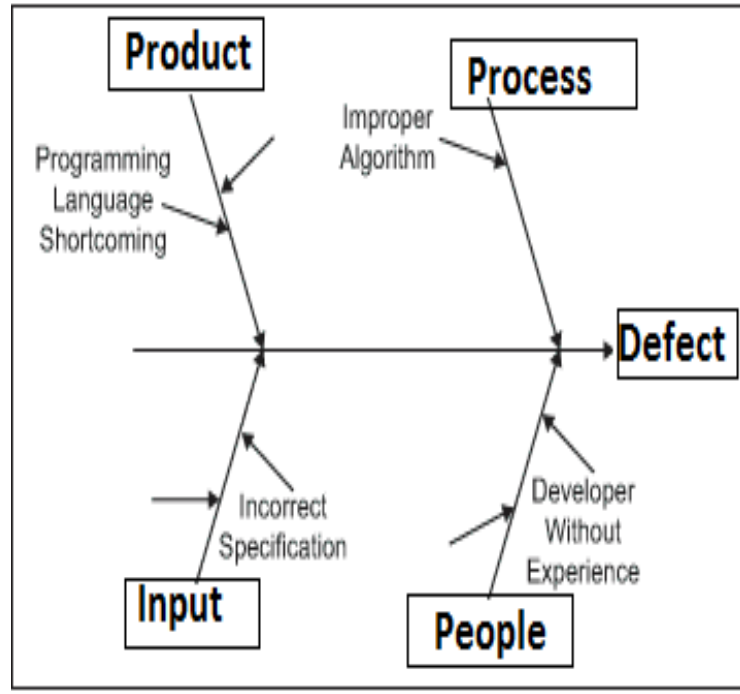

Fig 12 : Cause-and-Effect Diagram for a Defect list

Cause-and-effect diagram for a defect is given in figure 12 . Discovering and killing the reason would keep the issue from repeating. Discovering the reasons and disposing of them are similarly critical.

The causes are that can lead to increase in the customer quality requirement and in the variances, product and process. The Failure Modes and Effects Analysis (FMEA) were subsequently carried out (Table I) to arrive at a plan for prevention of causes of failure. FMEA is a tool that helps to prevent the occurrence of problems by identifying the potential failure modes in which a process or product may fail to meet specifications, and rating the severity of the effect on the customer, providing an objective evaluation of the occurrence of causes, determining the ability of the current system to detect when those causes or failure modes will occur. Based on the above factors, a Risk Priority Number (RPN) for each failure mode is calculated.

\subsection{Improve}

\subsubsection{Why-Why analysis}

Shows a why-why diagram which helped in identifying root cause of the problem.

3.4.2 Failure Mode and Effects Analysis (FMEA) The major causes, prioritized on the basis of RPN, which is shown in table 1 are Programming Language short Coming, Missing Conditions, Improper Algorithm, Incorrect Scope, Developer without Experience, New Requirement.

\section{Programming Language short Coming}

Programming languages are not according to the value of the product.

$$
\text { Why }
$$

There is a chance that the required conditions are missing

Why<smiles>C[14CH3]</smiles>

There is a chance that Algorithm is improper<smiles>[13CH3][131InH2]</smiles>

There is a chance of Developer without Experience There is a chance that the Incorrect Scope of new requirement
could lead to defects.

These are the causes for which the actual solutions can be implemented by improving the five domains of sustainability.

(i) Improve the quality requirements to reduce variance in the value of the product.

(ii) Need of reduced variances in process.

(iii) Improved quality of product.

(iv) Lack Customer quality requirements, Maintenance and reliability in the process.

(v) Need of new technologies, fulfillment of new requirements.

(vi) Manage the efficiency and reusability of product and process.

The following recommendations are followed and it results in several processes and product improvements in the Requirement: In the process development Improvement in yield and sigma value, reduce the variances and fulfil the quality requirement without affecting the human surrounding and it has not any negative impact on our health and welfare.

- Need of optimization of resource usage during software development tasks, taking into account the energy of used equipment (hardware and software). In our product we select such material which has minimum dependence on natural resources where less energy will be used.

- Those indicators should be selected which are representing all five sustainability domains. In order to select indicators it is useful to classify them according to requirement of product and process. Such a classification scheme is referred to as a taxonomy. The most widely used taxonomy is based 
on the three Domains of sustainability but efforts are being made to introduce five domains.

\subsection{Control Phase}

Control Phase will execute the last change devices, arrangements and guarantee their execution to be accurate. [22]We can explain with control chart of one month that reduce the variances and fulfil the quality requirement by checking and controlling the procedure, guarantees for Quality assurance and hardware accuracy that it works at its maximum capacity.

\section{Checking And Controlling for} Procedure gurantee of Quality

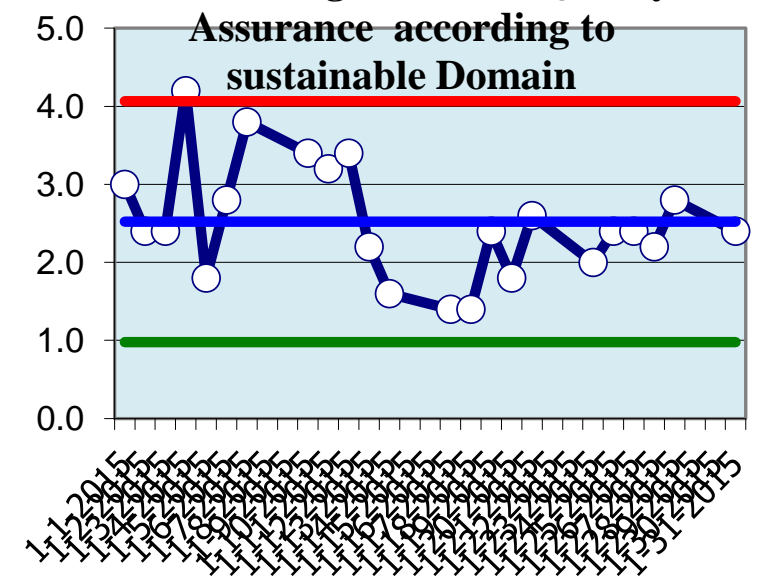

Fig 13: Checking and Controlling for Procedure guarantee of Quality Assurance according to sustainable Domains

The Figurer 13 distinguishes the approaches to check the equipment precision and give the quality affirmation. An important part of Statistical Process Control (SPC) is monitoring the production process to make sure that the only variations in the process are those due to common or normal causes. Under these conditions it can predict that a production process is in a state of control. [23]

\section{CONCLUSION}

The results obtained after the implementation of the improved measures which are described below:

1. Improvement in Sigma Level - The sigma level has been increased to 3.9(corresponding to improved process yield of $99.19 \%$ ) from 3(previous process yield of $90.01 \%$ ). The higher the Sigma level, the better the process is performing and the lower the probability that a defect will occur. The DMAIC methodology of Six Sigma has resulted into a quantum improvement in Sigma value.

2. Customer satisfaction impact by Quality Requirement - Customer satisfaction is achieved by providing the products and process which guarantee for quality assurance and hardware accuracy that it works at its maximum capacity. By selecting five dimension indicators and providing defect- free products and process of consistent performance and quality, the Six Sigma practice definitely enhanced the customer satisfaction

3. Improvement in yield/productivity -The yield or productivity is improved by optimum utilization of resources along with the reduction in the wastages and it will be more useful with five dimension indicators. Higher productivity leads to more production, lower cost of production and better quality and competitiveness in the marketplace.

4. Cost of production, better quality and competitiveness in the marketplace.

For future work, we will complete the change of the SSS and apply it to the real Six Sigma undertaking to exhibit its ampleness and capability

Table 1. Process Fmea Analysis

\begin{tabular}{|c|c|c|c|c|c|c|c|}
\hline $\begin{array}{l}\text { Sr. } \\
\#\end{array}$ & $\begin{array}{l}\text { Potential } \\
\text { Failure } \\
\text { Mode }\end{array}$ & $\begin{array}{l}\text { Potential } \\
\text { Failure } \\
\text { Causes }\end{array}$ & Potential Failure Effects & Severity & Occurrence & Detection & RPN \\
\hline 1 & $\begin{array}{l}\text { Value } \\
\text { Product }\end{array}$ & $\begin{array}{l}\text { Programming } \\
\text { Language } \\
\text { short Coming }\end{array}$ & $\begin{array}{l}\text { Targets not fulfilled according } \\
\text { to the Sustainable } \\
\text { development and variances in } \\
\text { products }\end{array}$ & 13 & 9 & 8 & 936 \\
\hline 2 & $\begin{array}{ll}\text { Value } & \text { of } \\
\text { Process } & \end{array}$ & $\begin{array}{l}\text { Missing } \\
\text { Conditions }\end{array}$ & $\begin{array}{l}\text { Unable to get Quantifiable } \\
\text { output to according new } \\
\text { approaches }\end{array}$ & 14 & 8 & 7 & 784 \\
\hline 3 & $\begin{array}{l}\text { Process } \\
\text { quality } \\
\text { requirements }\end{array}$ & $\begin{array}{l}\text { Improper } \\
\text { Algorithm }\end{array}$ & $\begin{array}{l}\text { Developer } \\
\text { requirements are not fulfilled } \\
\text { according to sustainable } \\
\text { development and variances in } \\
\text { the process }\end{array}$ & 10 & 8 & 8 & 664 \\
\hline 4 & $\begin{array}{l}\text { Realists } \\
\text { objective is } \\
\text { not defined } \\
\text { properly }\end{array}$ & $\begin{array}{l}\text { Incorrect } \\
\text { Scope }\end{array}$ & $\begin{array}{l}\text { Sustainable software is not } \\
\text { achieved }\end{array}$ & 10 & 7 & 8 & 560 \\
\hline 5 & $\begin{array}{l}\text { Maintenance } \\
\text { and }\end{array}$ & $\begin{array}{l}\text { Developer } \\
\text { without }\end{array}$ & $\begin{array}{l}\text { Customer quality requirements } \\
\text { are not fulfilled according to }\end{array}$ & 13 & 8 & 4 & 416 \\
\hline
\end{tabular}




\begin{tabular}{|c|l|l|l|c|c|c|c|}
\hline & $\begin{array}{l}\text { reliability in } \\
\text { process }\end{array}$ & Experience & sustainable development & & & \\
\hline 6 & $\begin{array}{l}\text { Need of } \\
\text { advanced } \\
\text { instrument }\end{array}$ & $\begin{array}{l}\text { New } \\
\text { Requirement }\end{array}$ & $\begin{array}{l}\text { Define standard are not enough } \\
\text { for the development of } \\
\text { sustainability }\end{array}$ & 10 & 7 & 4 & 280 \\
\hline
\end{tabular}

\section{REFERENCES}

[1] Greene, R. L., Professional Ethics and the NCEES. Presented at the OEC International Conference on Ethics in Engineering and Computer Science, March 1999.

[2] United Nations General Assembly. 1987. Report of the World Commission on Environment and Development: Our Common Future. Transmitted to the General Assembly as an Annex to document A/42/427 Development and International Co-operation: Environment. June 1987, Geneva, Switzerland.

[3] 5-ways-to-improve-quality.html. Retrieved from www.inc.com/guides/2010/09/

[4] Shrivastava, P. ,The Role of Corporations in Achieving Ecological Sustainability. The Academy of Management Review, Vol. 20, No. 4 (Oct., 1995), pp. 936-960.

[5] Capra E., and Merlo, F. 2009 Green IT: Everything Starts from the Software. Proceedings of the 17th European Conference on Information Systems (ECIS 2009). 8-10 june Verona, Italy. pp. 62-73.

[6] Zhong, B.; Feng, M. and Lung, C-H. A Green Computing Based Architecture Comparison and Analysis, Proceeding of the GREENCOM-CPSCOM '10 Proceedings of the 2010 IEEE/ACM Int'l Conference on Green Computing and Communications \& Int'l Conference on Cyber, Physical and Social Computing, Pages 386-391

[7] Albertao, F. (2004) Sustainable Software Engineering.

[8] http://www.scribd.com/doc/5507536/SustainableSoftware-Engineering\#about. Accessed 30 Nov 2010

[9] Penzenstadler, B. ; Bauer, V. and Calero, C. , Sustainability in software engineering: A systematic literature review for building up a knowledge base, tech. rep., Technische Universit at Munchen, 2012.

[10] Lami G., Fabbrini F., and Fusani, M., 2012. Software Sustainability from a Process-Centric Perspective, Proceedings of EuroSPI 2012, Vienna (Austria), June 2012. Communication in Computer and Information Science CCIS n. 301, D. Winkler, R.V. O'Conner, R. Messnarz (eds.), Springer 2012, pp. 97-108.Dobson. A., Environment sustainabilities: An Analysis and a typology, Environmental Politics 5(3), 08 Nov 2007, pages 401-428

[11] Burger, P. and Christen. M., Towards a capability approach of sustainability. Journal of Cleaner Production, 19, 2001

[12] Amsel, N.; Ibrahim, Z.: Malik, A.; and Tomlinson. B.., Toward sustainable software engineering, ICSE: Proceedings of the 33rd International Conference on Software Engineering. Waikiki, Honolulu, HI, USA, pp: 976-979, 2011
[13] Lomborg 2001, 32, reports of World Bank's environmental sustainability, retrieved from www.softwaresixsigma.com

[14] Gibson, R.B. Specification of Sustainability-based Environmental Assessment Decision Criteria and Implications for Determining "Significance" in Environmental Assessment; Paper prepared under a contribution agreement with the Canadian Environmental Assessment Agency Research and Development Programme ,Ottawa, Canada, 2001

[15] Robert, K.-H.; Schmidt-Bleek, B.; Aloisi de Larderel, J.; Basile, G.; Jansen, J.L.; Kuehr, R.; Price Thomas, P.; Suzuki, M.; Hawken, P.; Wackernagel, M. Strategic sustainable development /selection, design and synergies of applied tools. Journal of Cleaner Production, 10 (3), 197-2142002

[16] Lecture Notes: MS3.1. Software Engineering Concepts and Implementation from Centre for Information Technology and Engineering, Manonmaniam Sundaranar University Retrieved from www.msuniv.ac.in/soft.pdf

[17] Aized,T,TOTAL QUALITY MANAGEMENT AND SIX SIGMA. Retrieved from www.mescenter.ru

[18] Marshall, J., Lecture notes on An Introduction to Design for Six Sigma concepts: Product Excellence using 6 Sigma Module, The University of Warwick.

[19] Gallopín, G., A systems approach to sustainability and sustainable development, Sustainable Development and Human Settlements Division ECLAC/ Government of the Netherlands Project NET/00/063 "Sustainability Assessment in Latin America and the Caribbean"medio ambiente y desarrollo 64 Santiago, Chile, March, 2003 ,Retrieved from http://www.cepal.org/en/publications/5759-systemsapproach-sustainability-and-sustainable-development

[20] Owens, T., (2012). How I can apply Six Sigma in a software development environment?

[21] Defect-prevention-reducing-costs-and-enhancing-quality. Retrieved from

[22] http://www.isixsigma.com/industries/software-it/

[23] Defect prevention: Reducing costs and enhancing quality.

[24] retrievedfromhttp://www.ieeetmc.org/itmc2014-tutorials.

[25] DMAIC_Process_Improve_Phas...Six Sigma DMAIC Process - Improve Phase - Failure Mode Effect Analysis (FMEA) - International Six Sigma Institute.Retrieved from http://www.sixsigma.institute.org/Six_Sigma_ 